\title{
Seasonal Fluctuations of Some Enzymes Relating to Sucrose and Sorbitol Metabolism in Peach Fruit
}

\author{
Takaya Moriguchi, Tetsuro Sanada, and Shohei Yamaki' \\ Division of Breeding, Fruit Tree Research Station, Tsukuba, Ibaraki, 305 Japan
}

Additional index words. Prunus persica, sucrose synthase, sucrose phosphate synthase, invertase, sorbitol oxidase,
sucrose, sorbitol, sugar

\begin{abstract}
Sugar levels and composition were determined in developing 'Hakuto' peach (Prunus persica Batsch var. vulgaris Maxim.) fruit. Glucose and fructose in nearly equal amounts were the predominant sugars detected during the early stage of development. Sucrose subsequently began to accumulate and was the predominant sugar in mature fruit. Sorbitol remained at a low level throughout development. The large increase in the amount of sucrose was accompanied by a rapid increase in sucrose synthase (EC 2.4.1.13) activity. Sucrose phosphate synthase (EC 2.4.1.14) was also detected in flesh extracts, but the activities were low throughout development. Acid invertase (EC 3.2.1.26) activity was highest in young fruit and declined with development. Activity, however, increased again at a later stage of development. Peach fruit contained appreciable sorbitol oxidase activity, while other sorbitol-related enzymes were barely detectable, suggesting that transported sorbitol was predominantly converted to glucose. These results suggest that the supply of glucose and fructose depends on acid invertase and sorbitol oxidase, and that accumulation of sucrose depends on-sucrose synthase.
\end{abstract}

In the Rosaceae family, including peach, sorbitol plays an important role in the translocation of "photosynthate (Bieleski, 1969; Reid and Bieleski, 1974; Webb and Burley, 1962), but is subsequently converted to other sugars in fruit. Mature peach fruit is characterized by high sucrose content (Ishida et al., 1971). Sucrose content in young peach fruit is low, then rapidly rises to account for $>70 \%$ of total soluble sugars at maturation (Kakiuchi et al., 1981). Therefore, it is of interest to determine the metabolic fate of transported sugars (sorbitol and sucrose) during fruit development.

Organs that store sucrose, such as sugarbeet root (Giaquinta, 1979), sugar cane stem (Hatch et al., 1963), citrus fruit (Kato and Kubota, 1978), and Cucumis melo (Schaffer et al., 1987) grow actively early in development, and subsequently accumulate sucrose as they develop. This transition is characterized by changes in sucrose metabolism (Schaffer et al., 1987). The actively growing stage is usually characterized by relatively high acid invertase activity, although, at maturity, its activity is low. In contrast, sucrose synthase activity increases with maturation (Giaquinta, 1979). In the fruit of apple (Yamaki and Ishikawa, 1986) and Japanese pear (Yamaki and Moriguchi, 1989), activity of $\mathrm{NAD}^{+}$-dependent sorbitol dehydrogenase, which converts sorbitol to fructose, fluctuates with sucrose accumulation. The purpose of the work reported here was to characterize the activity of sucrose synthase, sucrose phosphate synthase, and invertase- and sorbitol-related enzymes during peach fruit development and to determine the possible relationship between their activities and fruit sugar composition.

\section{Materials and Methods}

Plant material. Samples of 20 to 60 fruit were harvested from 9-year-old 'Hakuto' peach trees at 8:00 AM from May to Aug.

Received for publication 14 Feb. 1989. We are grateful to S. Murase, Second Laboratory of Pomology, Fruit Tree Research Station, for supplying peach fruit. We are also grateful to K. Motoyoshi for her kind help in the sugar analysis. This paper is contribution A-245 of the Fruit Tree Research Station. The cost of publishing this paper was defrayed in part by the payment of page charges. Under postal regulations, this paper therefore must be hereby marked advertisement solely to indicate this fact.

'Present address: Laboratory of Horticulture, School of Agriculture, Nagoya University, Chikusa, Nagoya, 464 Japan.
1988. A portion of each fruit was subsampled and diced into small pieces. Fruit samples ranging from 9 to $50 \mathrm{~g}$ fresh weight were used for enzyme assays and sugar determination. All enzyme assay values and sugar determinations were based on two replicate samples.

Determination of sugar content and composition. Sugars extracted in $80 \%$ ethanol were converted to trimethyl silyl (TMS) derivatives. The derivatives were injected into a gas-liquid chromatography (GC-9A, Shimadzu, Tokyo) equipped with a capillary column (CP-Sil 8CB, Gasukuro Kogyo Inc., Tokyo) to determine their amount and composition.

Enzyme extraction and assay. Sucrose synthase and sucrose phosphate synthase were extracted by homogenizing peach fruit in $0.2 \mathrm{M} \mathrm{K}$-phosphate buffer ( $\mathrm{pH} \mathrm{7.8)} \mathrm{containing} 10 \mathrm{~mm} \mathrm{~K}$ ascorbate, $5 \mathrm{~mm} \mathrm{MgCl}, 1 \mathrm{~mm}$ EDTA, $1 \mathrm{~mm}$ dithiothreitol (DIT), and $10 \%$ polyvinylpolypyrrolidone (PVPP). After centrifugation at $10,000 \times g$ for 20 rein, the supernatant was passed through a Sephadex G-25 column to remove phenolic compounds and the filtrate precipitated with ammonium sulfate. The precipitate was then dialyzed against $0.01 \mathrm{M}$ Tris-HCl buffer (pH 7.2) containing $1 \mathrm{~mm}$ DTT. Sucrose synthase and sucrose phosphate synthase activity were assayed at 30C by the method described previously (Moriguchi and Yamaki, 1988). Reaction mixtures contained $2 \mathrm{mM}$ UDPG (uridine 5'-diphosphoglucose), $15 \mathrm{mM}$ fructose, $5 \mathrm{mM} \mathrm{MgCl}_{2}$, and $15 \mathrm{mM}$ Hepes-KOH buffer $(\mathrm{pH} \mathrm{8.5)}$. The total volume of the sample was $1.2 \mathrm{ml}$. In the case of sucrose phosphate synthase, fructose-6-phosphate and Hepes-KOH buffer ( $\mathrm{pH} 7.5)$ were substituted for fructose and Hepes-KOH buffer ( $\mathrm{pH} 8.5$ ), respectively. In addition, $1.3 \mathrm{mM}$ $\mathrm{NaF}$ was added to the reaction mixture. Sucrose or sucrose-P was determined by the method of Roe (1934). Data are expressed as micromoles of sucrose or sucrose-P produced per hour.

Acid invertase and sorbitol oxidase were extracted by homogenizing peach fruit in $0.1 \mathrm{M} \mathrm{K}$-phosphate buffer ( $\mathrm{pH} 7.0$ ) containing $10 \mathrm{mM} \mathrm{K}$-ascorbate, $1 \mathrm{mM}$ DIT, and $0.3 \%$ Triton $\mathrm{X}-100$. The homogenate was centrifuged at $10,000 \times \mathrm{g}$ for 20 min. The precipitate was homogenized again with $0.1 \mathrm{M} \mathrm{K}$ phosphate buffer ( $\mathrm{pH} 7.0$ ) containing $10 \mathrm{~mm} \mathrm{~K}$-ascorbate, $1 \mathrm{~mm}$ DTT, and $0.5 \mathrm{M} \mathrm{NaCl}$, then recentrifuged at $10,000 \times \mathrm{g}$ for 20 min. The combined supernatant was fractionated with ammonium sulfate. The precipitated protein was dialyzed against 0.01 
$\mathrm{M}$ Tris- $\mathrm{HCl}$ buffer ( $\mathrm{pH}$ 7.0) containing 1 mM DTT and the soluble fraction analyzed for soluble acid invertase and sorbitol oxidase activity. The residue remaining after centrifugation was dialyzed against the same buffer and analyzed for bound acid invertase and sorbitol oxidase activity. Acid invertase and sorbitol oxidase activities were assayed by determining the amount of glucose produced from sucrose and sorbitol, respectively, according to the enzyme-coupling method of Yamaki (1980). The reaction of acid invertase was carried out at $30 \mathrm{C}$ in $1.7 \mathrm{ml}$ of a reaction medium composed of $59 \mathrm{~mm}$ acetate buffer $(\mathrm{pH}$ 5.0) and $70 \mathrm{~mm}$ sucrose. In the case of sorbitol oxidase, $59 \mathrm{~mm}$ acetate buffer ( $\mathrm{pH} 4.0$ ) and $235 \mathrm{~mm}$ sorbitol were employed. The reaction was stopped by boiling the mixture after adding 1 $\mathrm{ml}$ of $0.1 \mathrm{M}$ Tris-HCl buffer ( $\mathrm{pH} 8.0$ ) to $0.5 \mathrm{ml}$ of the reaction mixture. Data have been expressed as nano- or micromoles of glucose produced per hour.

Extraction and assay of sorbitol-6-P dehydrogenase, NAD ${ }^{+}$ dependent sorbitol dehydrogenase and $\mathrm{NADP}^{+}$-dependent sorbitol dehydrogenase were conducted according to the method of Yamaki and Ishikawa (1986).

\section{Results}

Sugar accumulation. Sucrose levels per gram fresh weight of peach fruit remained constant during the immature stage (Fig. 1). They rose rapidly as fruit matured (4 July) and became the major component $(>70 \%$ ) of total accumulated sugars in mature fruit. In fruit at the immature stage, glucose and and fructose were the predominant sugars. They were present in nearly equal amounts and thereafter remained constant. Sorbitol remained about constant at $5 \mathrm{mg} \cdot \mathrm{g}^{-1}$ fresh weight throughout all developmental stages and comprised $4 \%$ of total sugars in mature fruit.

Sucrose synthase and sucrose phosphate synthase activity.

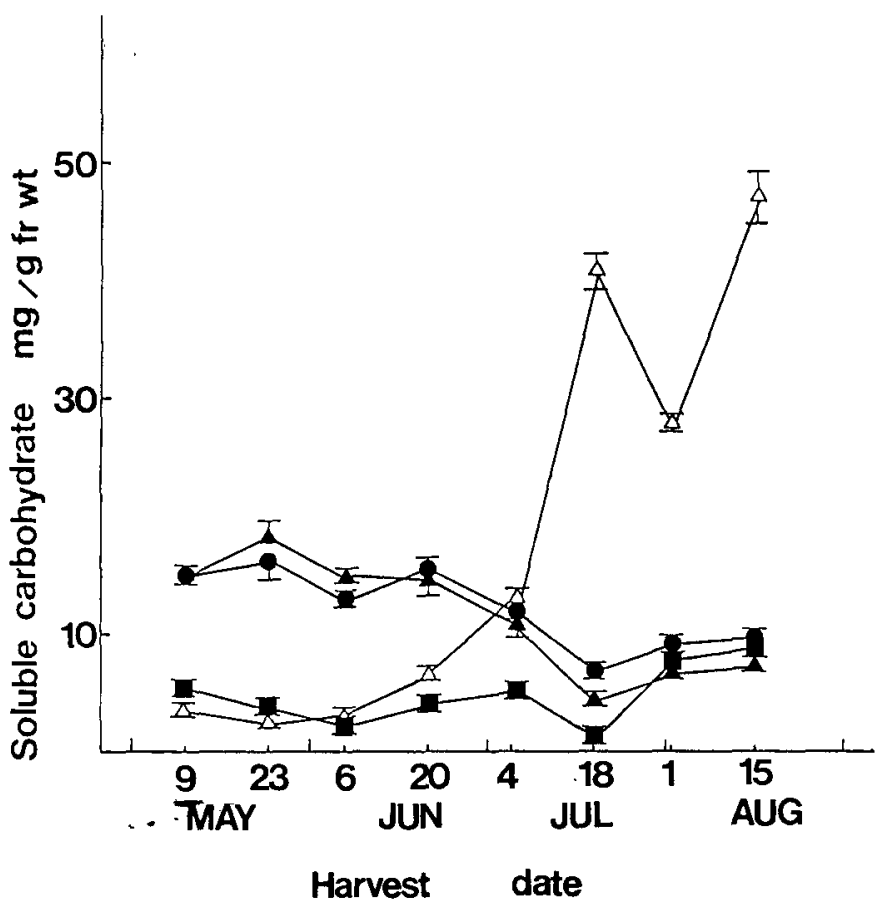

Fig. 1. Seasonal changes in soluble carbohydrates in peach fruit. $=$ Fructose, $\boldsymbol{\Lambda}=$ glucose $\boldsymbol{\nabla}=$ sorbitol, $\Delta=$ sucrose. Carbohydrate content is expressed as $\mathrm{mg} \cdot \mathrm{g}^{-1}$ fresh weight. Each point is the mean \pm SE of two observations.
Sucrose synthase activity per gram fresh weight was higher than the activity of sucrose phosphate synthase (Fig. 2). Its activity was high in immature fruit, then declined rapidly with fruit enlargement. Activity rose successively after this, accompanying sucrose accumulation, and reached its maximum on 18 July. This result was in contrast to sucrose phosphate synthase activity, which remained roughly constant at about a tenth of the sucrose synthase activity measured during the stage of maximum sucrose accumulation.

Invertase activity. Acid invertase was composed of two types, bound and soluble. During the immature stage, activity of the bound enzyme was roughly equal to the soluble one, but the bound fraction was predominant at ripening. Total activity of soluble and bound invertase was high in young fruit and declined rapidly with development to a level $<10 \%$ of that in young fruit (Fig. 3). The activity then increased again from 1 to $15 \mathrm{Aug}$. (the fruit ripening period), although it was very low compared with that in young fruit.

Sorbitol oxidase activiy. Sorbitol oxidase activity in both soluble and bound fractions was measured. In the immature stage, $\approx 50 \%$ of total activity was from the bound fraction, while, at the mature stage, $\approx 70 \%$ was from this fraction (Fig. 4). The total activity, based on fresh weight, was lower than that of the other enzymes measured. The activity was high in the immature fruit, decreasing prior to sucrose accumulation, then again rising slightly as fruit developed. This rise resulted from an increase in the bound fraction.

\section{Discussion}

Activity of sucrose synthase was much higher than that of the other enzymes measured. Sucrose synthase activity was high during the immature stage. We attribute this high activity to the supply of UDPG, a precursor of polysaccharide biosynthesis. Sucrose synthase activity rose again during the stage of sucrose accumulation. In a kinetic study (Moriguchi and Yamaki, 1988), sucrose synthase purified from mature peach fruit had a higher

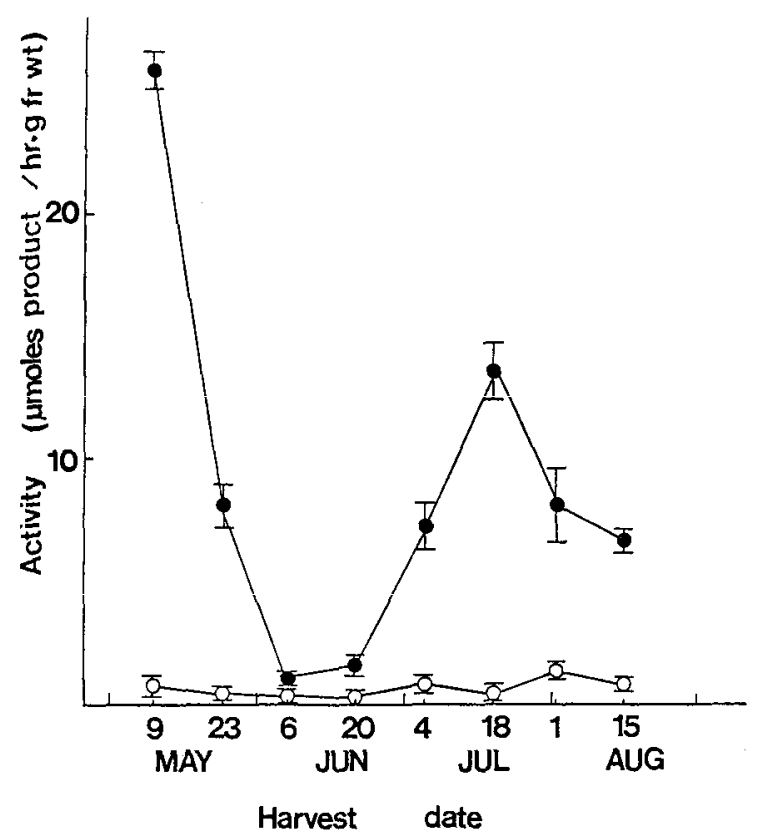

Fig. 2. Seasonal changes in sucrose synthase (-) and sucrose phosphate synthase $(O)$ activity per gram of fresh weight in peach fruit. Each point is the mean \pm SE of two observations. 


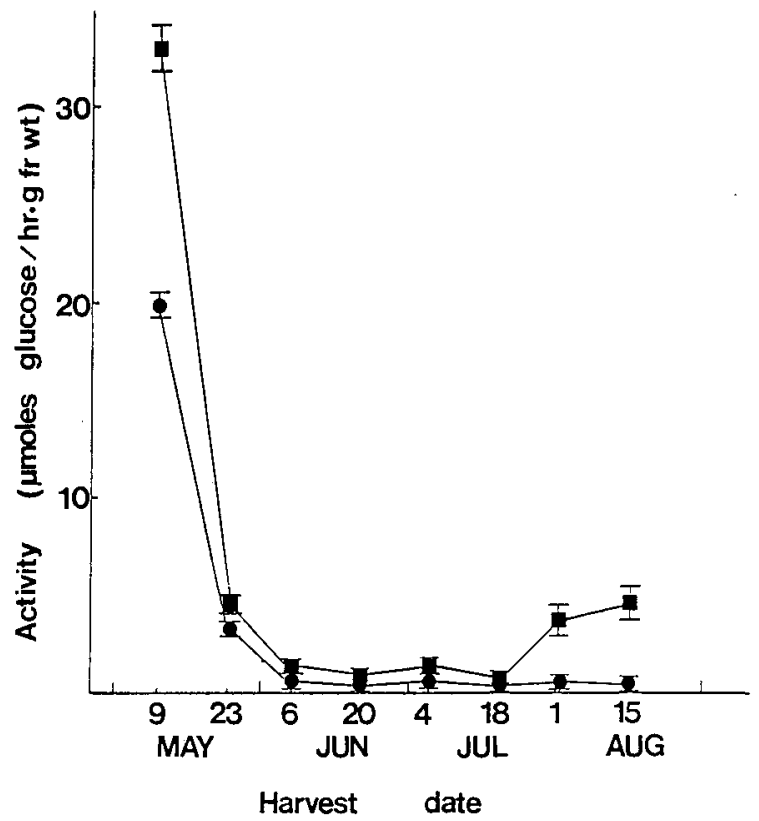

Fig. 3. Seasonal changes in acid invertase activity in peach fruit. $=$ Activity of soluble form per gram of fresh weight, $\square=$ Total activity of bound and soluble forms per gram fresh weight. Each point is the mean \pm SE of two observations.

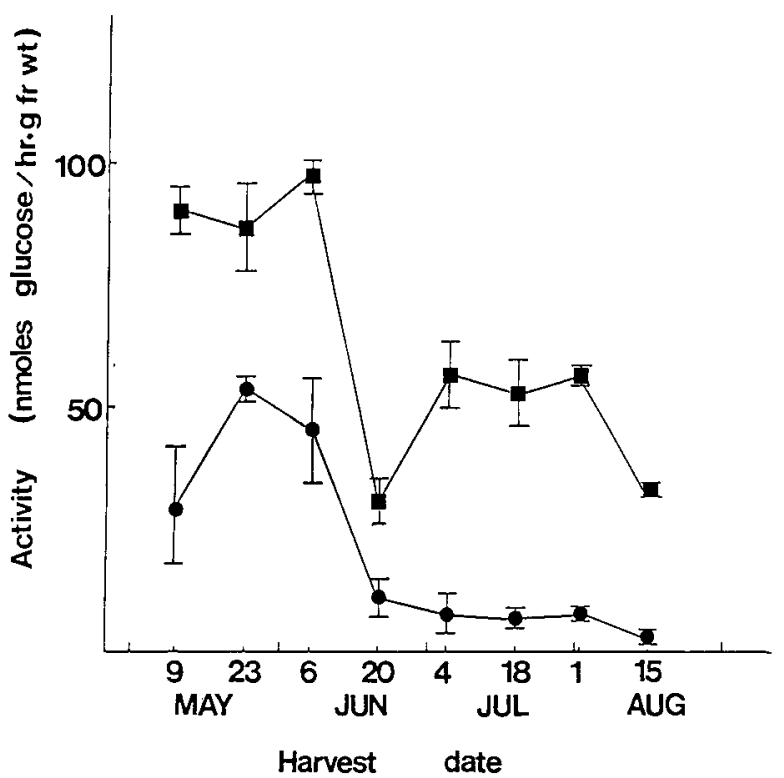

Fig. 4. Seasonal changes in sorbitol oxidase activity in peach fruit. = Activity of soluble form per gram of fresh weight, $\mathbf{\square}=$ Total activity of bound and soluble forms per gram of fresh weight. Each point is the mean $\pm \mathrm{SE}$ of two observations.

affinity for fructose than sucrose. The $\mathrm{K}_{\mathrm{m}}$ value for fructose was calculated to be $4.8 \mathrm{mM}$, while that for sucrose was $62.5 \mathrm{~mm}$ Other kinetic factors also suggested that the enzyme predominantly catalyzed sucrose synthesis. In contrast, sucrose phosphate synthase, which is presumed to be the major sucrosesynthesizing enzyme (Hawker, 1985), remained at a low level throughout peach fruit development. Recently, Kohler et al. (1988) reported that careful determination of sucrose phosphate synthase activity was necessary, since the enzyme is very un- stable. We compared the activity of the enzyme extracted according to their method with that described in this paper and found that the activity of sucrose phosphate synthase was the same irrespective of the method. A low activity of sucrose phosphate synthase (SPS) in peach fruit was not caused by inactivation during preparation, since SPS activity in wheat leaves was not reduced when the enzyme containing high SPS activity was extracted with peach fruit (data not shown). Thus, the increased sucrose level in mature fruit resulted from increased sucrose synthase activity. Sucrose accumulation in muskmelon (McCollum et al., 1988) and cucumber peduncles (Gross and Pharr, 1982) has also been demonstrated to result from sucrose synthase.

Acid invertase activity has been negatively correlated with sucrose accumulation in organs that store sucrose. Immature sugarbeet root (Giaquinta, 1979) and immature citrus fruit (Kato and Kubota, 1978) contained high soluble acid invertase activity that disappeared prior to sucrose accumulation. Moreover, high invertase activity was correlated with rapid growth of stem tissue in sugar cane, but was barely detectable as sucrose accumulated (Hatch et al., 1963). In contrast, Manning and Maw (1975) found that, in tomato fruit, which accumulate little sucrose, acid invertase activity increased as fruit ripened and was highest in overripe fruit. Acid invertase activity has been reported to be high in rapidly growing tissues such as shoot apices, root tips, and flowers (Claussen, 1977). This increased activity may occur because such organs need ample supplies of hexose sugars as energy sources. High invertase activity in immature fruit of peach corresponded to the time when cell division was occurring, but, in mature fruit, acid invertase increased in activity when sucrose was also accumulating. This relationship indicates that sucrose accumulation in mature peach fruit was not the result of reduced acid invertase activity.

Sorbitol oxidase, which catalyzes the conversion of sorbitol to glucose, was the predominant enzyme of sorbitol metabolism in peach fruit, but activities were too low to explain in vivo sorbitol interconversion. $\mathrm{NAD}^{+}$-dependent sorbitol dehydrogenase, sorbitol-6-P dehydrogenase, and $\mathrm{NADP}^{+}$-dependent sorbitol dehydrogenase activities, however, were barely detectable (data not shown). Sorbitol oxidase activity was two to three times higher than that in pear fruit (Yamakai and Moriguchi, 1989). However, NAD '-dependent sorbitol dehydrogenase has been shown to be a predominant enzyme during development of apple and Japanese pear fruit (Yamaki and Ishikawa, 1986; Yamaki and Moriguchi, 1989). Thus, transported sorbitol may be metabolized differently in peach than in apple and pear.

Our results show that there is an apparent relationship between sugar composition and relative enzyme activities during sucrose accumulation in developing peach fruit. Transported sorbitol was apparently converted to glucose by sorbitol oxidase. Glucose and fructose, products of acid intervase and sorbitol oxidase activity, were converted to sucrose by sucrose synthase.

\section{Literature Cited}

Bieleski, R.L. 1969. Accumulation and translocation of sorbitol in apple phloem. Austral. J. Biol. Sci. 22:611-620.

Claussen, W. 1977. Netto-photosyntheseraten sowie Saccharose- und Starkestoffwechsel in unterschiedlich alten Blättern der Aubergine (Solanum melongena L.). Angew. Bot. 51:129-141.

Giaquinta, R.T. 1979. Sucrose translocation and storage in the sugar beet. Plant Physiol. 63:828-832.

Gross, K.C. and D.M. Pharr. 1982. A potential pathway for galactose 
metabolism in Cucumis sativus L., a stachyose transporting species. Plant Physiol. 69:117-121.

Hatch, M. D., J.A. Sacher, and K.T. Glasziou. 1963. Sugar accumulation cycle in sugar cane: I. Studies on enzymes of the cycle. Plant Physiol. 38:338-343.

Hawker, J.S. 1985. Sucrose, p. 1-51. In: P.M. Dey and R.A. Dixon (eds.). Biochemistry of storage carbohydrates in green plants. Academic, New York.

Ishida, M., A. Inaba, and Y. Sobajima. 1971. Seasonal changes in the concentration of sugars and organic acids in peach fruits. Sci. Rpt. Kyoto Pref. Univ. Agr. 23:18-23.

Kakiuchi, N., T. Tokita, K. Tanaka, and K. Matsuda. 1981. Relations between respiration, ethylene formation, chemical components and maturation of peaches (in Japanese with English summary). Bul. Fruit Tree Res. Sta. (Ministry Agr. For. Fisheries, Japan) A 8:5777.

Kate, T. and S. Kubota. 1978. Properties of invertases in sugar storage tissues of citrus fruit and changes in their activities during maturation. Physiol. Plant. 42:67-72.

Kohler, J., E. Komor, M. Thorn, and A. Maretzki. 1988. Activity of sucrose-phosphate synthase in sugar cane leaves. Photochemistry 22:1605-1608.

Manning, K. and G.A. Maw. 1975. Distribution of acid invertase in the tomato plant. Photochemistry 14:1965-1969.

McCollum, T. G., D.J. Huber, and D.J. Cantliffe. 1988. Soluble sugar accumulation and activity of related enzymes during muskmelon fruit development. J. Amer. Soc. Hort. Sci. 113:399-403.

Moriguchi, T. and S. Yamaki. 1988. Purification and characterization of sucrose synthase from peach (Prunus persica) fruit. Plant \& Cell Physiol. 29:1361-1366.

Reid, M.S. and R. L. Bieleski. 1974. Sugar changes during fruit ripening-Whither sorbitol?, p. 823-830. In: R.L. Bieleski, A.R. Ferguson, and M.M. Cresswell (eds.). Mechanisms of regulation of plant growth. Royal Soc. New Zealand, Wellington. Bul. 12.

Roe, J.H. 1934. A colorimetric method for the determination of fructose in blood and urine. J. Biol. Chem. 107:15-22.

Schaffer, A. A., B. Aloni, and E. Fogelman. 1987. Sucrose metabolism and accumulation in developing fruit of Cucumis. Photochemistry 26:1883-1887.

Webb, K.L. and J.W.A. Burley. 1962. Sorbitol translocation in apple. Science 137:766.

Yamaki, S. 1980. Sorbitol oxidase converting sorbitol to glucose in apple leaf. Plant \& Cell Physiol. 69:117-121.

Yamaki, S. and K. Ishikawa. 1986. Roles of four sorbitol related enzymes and invertase in the seasonal alteration of sugar metabolism in apple tissue. J. Amer. Soc. Hort. Sci. 111:134-137.

Yamaki, S. and T. Moriguchi. 1989. Seasonal fluctuation of sorbitol related enzymes and invertase activities accompanying maturation of Japanese pear (Pyrus serotina Rehdervar.cults Rehder) fruit. J. Jpn. Soc. Hort. Sci. 57:602-607. 